\title{
Prevalence and Correlates of Muscle-Strengthening Activity Participation in Croatia: A Cross-Sectional Study in a National Representative Sample of 4561 Adults
}

\author{
Hrvoje Radašević ${ }^{1}$, Jelena Čvrljak ${ }^{1}$, Željko Pedišić ${ }^{2, *}$ and Danijel Jurakić ${ }^{3}$ \\ 1 Andrija Stampar Teaching Institute of Public Health, 10000 Zagreb, Croatia; \\ hrvoje.radasevic@stampar.hr (H.R.); jelena.cvrljak@stampar.hr (J.Č.) \\ 2 Institute for Health and Sport, Victoria University, Melbourne, VIC 80001, Australia \\ 3 Faculty of Kinesiology, University of Zagreb, 10000 Zagreb, Croatia; danijel.jurakic@kif.unizg.hr \\ * Correspondence: zeljko.pedisic@vu.edu.au
}

\section{check for} updates

Citation: Radašević, H.; Čvrljak, J.; Pedišić, Ž.; Jurakić, D. Prevalence and Correlates of Muscle-Strengthening Activity Participation in Croatia: A Cross-Sectional Study in a National Representative Sample of 4561 Adults. Int. J. Environ. Res. Public Health 2021, 18, 8905. https:// doi.org/10.3390/ijerph18178905

Academic Editor: Pantelis

T. Nikolaidis

Received: 8 July 2021

Accepted: 21 August 2021

Published: 24 August 2021

Publisher's Note: MDPI stays neutral with regard to jurisdictional claims in published maps and institutional affiliations.

Copyright: (c) 2021 by the authors. Licensee MDPI, Basel, Switzerland. This article is an open access article distributed under the terms and conditions of the Creative Commons Attribution (CC BY) license (https:/ / creativecommons.org/licenses/by/ $4.0 /)$.

\begin{abstract}
The World Health Organization recommends adults to engage in muscle-strengthening activity (MSA) at least two times per week. The aim of this study was to determine the prevalence and correlates of MSA in Croatian adults. We analysed self-reported data collected among 4561 Croatians aged $\geq 18$ years within the European Health Interview Survey (EHIS wave 2 ). We calculated the weighted prevalence of meeting the MSA guidelines, and odds ratios for different population groups, adjusted for a range of sociodemographic and lifestyle variables in a multivariable logistic regression analysis. The prevalence of meeting the MSA guidelines was $8.0 \%(95 \% \mathrm{CI}: 7.2,8.8)$ in the overall sample, $5.4 \%$ (95\% CI: 4.5, 6.4) among females, and 10.9\% (95\% CI: 9.6, 12.3) among males. We found significantly lower odds of meeting the MSA guidelines for females, older age groups, inhabitants of sparsely populated areas, those with a low education level, obese individuals, and those who did not rate their health as "very good" ( $p<0.05$ for all). The vast majority of Croatian adults do not meet the MSA guidelines. Public health initiatives to promote MSA in Croatia should focus on females, seniors, sparsely populated areas, people with low education, obese individuals, and those with impaired health.
\end{abstract}

Keywords: physical inactivity; motor activity; exercise; resistance training; surveillance

\section{Introduction}

Non-communicable diseases (NCDs) are among the most prevalent illnesses and are the leading cause of mortality worldwide [1]. It was estimated that physical inactivity is responsible for $6 \%$ to $10 \%$ of deaths from NCDs [2]. According to the World Health Organization (WHO)'s estimates, physical inactivity is the fourth highest ranked mortality risk factor globally [3]. Epidemiological studies have shown that physical activity can reduce the risk of a number of chronic diseases and conditions, such as coronary heart disease [4], hypertension [5], metabolic syndrome [6], and cancer [7]. Increased physical activity at the population level could therefore significantly improve population health [2]

Although physical activity guidelines largely focus on the benefits of aerobic physical activity, they also include recommendations for muscle-strengthening activities (MSA) [8-10]. MSA are physical activities that are performed to increase the strength, power, endurance, and/or mass of skeletal muscles [11]. Usually, they are part of an exercise routine and involve the use of hand-held weights, weight machines, exercise bands, or the individual's own body weight (e.g., non-weight-bearing squats or push-ups) [12]. According to the current WHO physical activity guidelines, adults (18-64 years) and older adults ( $\geq 65$ years) should participate in MSA on two or more days a week [8]. In the recently proposed "Croatian 24-H Guidelines for Physical Activity, Sedentary Behaviour, and Sleep", adults and older adults are encouraged to engage in MSA at least two times a week [13]. 
Numerous studies have shown the health benefits of MSA, such as improvements in strength [14], physical performance [15], and physical functioning [16]. MSA may also help in the prevention of cardiovascular disease [17], prevention and treatment of type 2 diabetes [18], prevention or delay of obesity [19], preservation of bone and muscle mass [20], and the improvement of mental health [21]. Ciolac and Rodrigues da Silva [22] stated that MSA may be an effective treatment for rheumatoid arthritis, osteoarthritis, and low back pain, while Saeidifard et al. [23] found an association of MSA with lower mortality risk, especially if it is combined with aerobic exercise.

Studies on the prevalence and correlates of MSA have been conducted in several countries, such as Australia [24-26], the European Union member states [27], Finland [28], Japan [29], Korea [30], Scotland [31], and the United States [32-34]. These studies showed a varying prevalence of adults meeting the MSA guidelines, ranging between $0.7 \%$ in Romania and $51.6 \%$ in Iceland [27]. A recent systematic review on correlates of MSA included 51 studies from nine countries [35] and found that MSA participation was low among those with poor self-rated health and low education levels. Self-efficacy, affective judgments, self-regulation behaviours, subjective norms, and programme leadership were identified as factors that may promote MSA [35]. Findings of individual studies on the association between MSA and a range of potential correlates, such as age, sex, race, income, and body mass index (BMI), were inconsistent [35].

There are no published data on the correlates of MSA in Croatia. Liangruenrom et al. [36] suggested that correlates of physical activity may be country-specific. Given that the findings of previous studies on MSA participation and a number of its correlates are inconsistent, the aim of this study was to determine the prevalence and correlates of MSA in a national representative sample of Croatian adults. We hypothesised that the prevalence of meeting the MSA guidelines is low, and that it would vary significantly across different population groups.

\section{Materials and Methods}

We used data from the European Health Interview Survey (EHIS), a standardised survey on health status, health care use, and determinants of health that is conducted in all European Union member states every five years. EHIS was conducted in Croatia for the first time as a part of its second cycle (EHIS wave 2). The EHIS wave 2 was conducted in Croatia from April 2014 to March 2015 by the Croatian Institute of Public Health, in cooperation with county-level institutes of public health, the Central Bureau of Statistics, and the Ministry of Health. A two-stage stratified random sample of private dwellings was used to ensure that the sample was representative of the Croatian population. A total of 3140 private households were included in the sample. Persons who lived in collective households (e.g., nursing homes, boarding schools, hospitals, monasteries) were not included in the survey. The sample included all individuals within the selected households who were at least 15 years old at the time of the survey. Sampling was done by the Central Bureau of Statistics, based on data from the 2011 Census of Population, Households and Dwellings. The Ethics Committee of the Croatian Institute of Public Health approved the study (number: 80-581/1-14; 27 March 2014) and all respondents signed an informed consent form before participating in the study. Trained surveyors conducted faceto-face interviews with the study participants. The total sample included 5446 participants aged 15 to 96 years. For the purpose of this study, we used data from 4561 participants aged 18-96 years, who responded to the question about MSA. More details regarding EHIS wave 2 methods can be found elsewhere [37,38]. Sample characteristics are presented in Table 1. 
Table 1. Sample characteristics.

\begin{tabular}{|c|c|c|}
\hline Population Group & $n$ & $\%$ \\
\hline All & 4561 & 100.0 \\
\hline \multicolumn{3}{|l|}{$\operatorname{Sex}$} \\
\hline Female & 2401 & 52.6 \\
\hline Male & 2160 & 47.4 \\
\hline \multicolumn{3}{|l|}{ Age } \\
\hline $18-24$ years & 458 & 10.1 \\
\hline 25-39 years & 1068 & 23.4 \\
\hline 40-64 years & 2122 & 46.5 \\
\hline $65+$ years & 912 & 20.0 \\
\hline \multicolumn{3}{|l|}{ Urbanisation level } \\
\hline Densely populated area & 1164 & 25.5 \\
\hline Moderately populated area & 1424 & 31.2 \\
\hline Sparsely populated area & 1973 & 43.2 \\
\hline \multicolumn{3}{|l|}{ Education level } \\
\hline Low & 924 & 20.3 \\
\hline Medium & 2597 & 56.9 \\
\hline High & 979 & 21.5 \\
\hline \multicolumn{3}{|l|}{ Smoking status } \\
\hline Non-smokers & 3220 & 70.6 \\
\hline Smokers & 1333 & 29.2 \\
\hline \multicolumn{3}{|l|}{ Alcohol intake } \\
\hline Rarely or never & 2970 & 65.1 \\
\hline $2-3$ days per month & 437 & 9.6 \\
\hline $1-2$ days per week & 430 & 9.4 \\
\hline 3 or more days per week & 702 & 15.4 \\
\hline \multicolumn{3}{|l|}{ Body mass index } \\
\hline$<18.5$ & 87 & 1.9 \\
\hline $18.5-24.9$ & 1848 & 40.5 \\
\hline $25-29.9$ & 1801 & 39.5 \\
\hline$\geq 30$ & 825 & 18.1 \\
\hline \multicolumn{3}{|l|}{ Self-perceived health } \\
\hline Very good & 1080 & 23.7 \\
\hline Good & 1640 & 36.0 \\
\hline Fair & 1149 & 25.2 \\
\hline Bad or very bad & 662 & 14.5 \\
\hline
\end{tabular}

\subsection{Measures}

\subsubsection{Muscle-Strengthening Activity}

The EHIS wave 2 questionnaire asked respondents about their participation in MSA using the question: "In a typical week, on how many days do you carry out physical activities specifically designed to strengthen your muscles, such as doing resistance training or strength exercises?" According to the proposed Croatian MSA guidelines [13], data were categorised as: (i) "meeting the MSA guidelines" (MSA participation on $\geq 2$ days/week), or (ii) "not meeting the MSA guidelines" (MSA participation on <2 days/week).

\subsubsection{Correlates of Muscle-Strengthening Activity}

Data on sex, age, urbanisation level, education level, self-perceived health, smoking status, alcohol intake, height, and weight were collected using the standard EHIS questionnaire [37]. Urbanisation level was presented in three categories: (1) Densely populated area; (2) Moderately populated area; and (3) Sparsely populated area. Education level was expressed using three categories: (1) High level of education (including professional, undergraduate, graduate, and postgraduate); (2) Medium level of education (including high 
school and vocational training after high school that does not include higher education); and (3) Low level of education (including preschool and elementary school education). Selfperceived health was assessed on the following scale: (1) Very good; (2) Good; (3) Fair; (4) Bad or very bad. Smoking status was presented in two categories: (1) Non-smokers; and (2) Smokers. Alcohol intake was assessed using the following question: "In the past 12 months, how often did you drink alcoholic beverages of any kind?", with a 4-point response scale, ranging from: (1) Rarely or never to (4) $\geq 3$ days/week. Self-reported height and weight data were used to calculate BMI. According to their BMI, participants were categorised into the following categories: $<18.5 \mathrm{~kg} / \mathrm{m}^{2}$ (underweight); from $18.5 \mathrm{~kg} / \mathrm{m}^{2}$ to $24.9 \mathrm{~kg} / \mathrm{m}^{2}$ ("normal" weight); from $25 \mathrm{~kg} / \mathrm{m}^{2}$ to $29.9 \mathrm{~kg} / \mathrm{m}^{2}$ (overweight); and $\geq 30 \mathrm{~kg} / \mathrm{m}^{2}$ (obese).

\subsection{Statistical Analysis}

Data were analysed using IBM SPSS Statistics 25 (IBM Corp, Armonk, NY, USA). We calculated the prevalence of meeting MSA guidelines and its $95 \%$ confidence intervals ( $95 \% \mathrm{CI})$ for the overall sample and stratified by age, urbanisation level, education level, smoking status, alcohol intake, BMI categories, and self-perceived health. Multivariable logistic regression was used to analyse the associations between sociodemographic, health, and lifestyle-related variables and the meeting/not meeting of MSA guidelines. The analyses included the following explanatory variables: Sex (reference group [ref] = "males"); Age (ref = "18-24 years"); Urbanisation level ( $\mathrm{ref}=$ "densely populated area"); Education level (ref = "high"); Self-perceived health $($ ref = "very good"); BMI (ref = "'normal weight"); Smoking status (ref = "non-smokers"); and Alcohol intake (ref = "rarely or never"). Adjusted odds ratios and their $95 \%$ CIs were presented. In all statistical tests, a $p$-value of $<0.05$ was considered to indicate statistical significance. All analyses were conducted using sampling weights to ensure that the estimates were population representative. Missing data were imputed using the expectation-maximization algorithm [39].

\section{Results}

In the total sample, $8.0 \%$ (95\% CI: 7.2, 8.7) of participants met the MSA guidelines (Table 2). Unadjusted analysis revealed significant differences in the prevalence of meeting MSE guidelines between the groups by sex, age, urbanisation level, education level, alcohol intake, BMI, and self-perceived health $(p<0.001)$ (Table 2$)$. In the adjusted analysis, significant associations with meeting the MSA guidelines were found for sex, age, urbanisation level, education level, BMI, and self-perceived health $(p<0.05)$ (Table 3$)$.

Specifically, females had $49 \%$ (95\% CI: 34, 61) lower odds of meeting the MSA guidelines, compared with males. Compared with the youngest age group (18-24 years), other age groups had significantly lower odds of meeting the MSA guidelines, with adjusted odds ratios ranging from 0.49 (95\% CI: $0.36,0.68)$ for $25-39$-year-olds to 0.18 (95\% CI: $0.11,0.31$ ) for older adults (65+ years). Compared to the inhabitants of densely populated areas, those who lived in sparsely populated areas had 37\% (95\% CI: 16, 52) lower odds of meeting the MSA guidelines. The adjusted odds ratio for the inhabitants of medium populated areas was not significant. Compared with the "high education" group, the odds of meeting the MSA guidelines were 50\% (95\% CI: 36, 61) and 77\% (95\% CI: 62, 86) lower in the "medium education" and "low education" groups, respectively. Furthermore, compared with the group with "normal" weight (BMI from 18.5 to 24.9), the individuals classified as obese (BMI $\geq 30)$ had $45 \%$ (95\% CI: 14,64$)$ lower odds of meeting the MSA guidelines. No significant associations with meeting the MSA guidelines were found for being "underweight" (BMI < 18.5) and "overweight" (BMI from 25 to 29.9). Furthermore, the highest odds of meeting the MSA guidelines were found for those who rated their health as "very good". Compared to them, those who rated their health as "good", "fair", and "bad or very bad", respectively, had 28\% (95\% CI: 7, 45), 40\% (95\% CI: 14, 59), and 63\% ( $95 \%$ CI: 32,80$)$ lower odds of meeting the MSA guidelines. 
Table 2. Weighted ${ }^{a}$ prevalence of meeting the muscle-strengthening activity (MSA) guidelines ${ }^{b}$ across different population groups.

\begin{tabular}{|c|c|c|}
\hline Population Group & $\%$ Meeting MSA Guidelines $\left(95 \% \mathrm{CI}^{\mathrm{c}}\right)$ & \multirow[t]{2}{*}{$p^{\mathrm{d}}$} \\
\hline All & $8.0(7.2,8.7)$ & \\
\hline \multicolumn{3}{|l|}{ Sex } \\
\hline Female & $5.4(4.5,6.4)$ & \multirow[t]{2}{*}{$<0.001$} \\
\hline Male & $10.8(9.6,12.3)$ & \\
\hline \multicolumn{2}{|l|}{ Age } & \multirow{5}{*}{$<0.001$} \\
\hline $18-24$ years & $20.1(16.4,23.8)$ & \\
\hline $25-39$ years & $11.8(9.9,13.7)$ & \\
\hline 40-64 years & $5.7(4.7,6.6)$ & \\
\hline $65+$ years & $2.7(1.7,3.8)$ & \\
\hline \multicolumn{2}{|l|}{ Urbanisation level } & \multirow{4}{*}{$<0.001$} \\
\hline Densely populated area & $11.4(9.6,13.2)$ & \\
\hline Moderately populated area & $8.0(6.6,9.4)$ & \\
\hline Sparsely populated area & $5.9(4.9,7.0)$ & \\
\hline \multicolumn{2}{|l|}{ Education level } & \multirow{4}{*}{$<0.001$} \\
\hline High & $14.1(11.9,16.3)$ & \\
\hline Medium & $7.9(6.9,9.0)$ & \\
\hline Low & $2.1(1.1,3.0)$ & \\
\hline \multicolumn{2}{|l|}{ Smoking status } & \multirow{3}{*}{0.546} \\
\hline Non-smokers & $7.8(6.9,8.7)$ & \\
\hline Smokers & $8.3(6.8,9.8)$ & \\
\hline \multicolumn{2}{|l|}{ Alcohol intake } & \multirow{5}{*}{$<0.001$} \\
\hline Rarely or never & $6.9(6.0,7.8)$ & \\
\hline $2-3$ days per month & $12.4(9.3,15.4)$ & \\
\hline 1-2 days per week & $10.7(7.8,13.6)$ & \\
\hline 3 or more days per week & $8.1(6.1,10.1)$ & \\
\hline \multicolumn{2}{|l|}{ Body mass index } & \multirow{5}{*}{$<0.001$} \\
\hline$<18.5$ & $8.0(2.3,13.8)$ & \\
\hline $18.5-24.9$ & $10.2(8.8,11.6)$ & \\
\hline $25-29.9$ & $7.7(6.5,9.0)$ & \\
\hline$\geq 30$ & $3.4(2.2,4.6)$ & \\
\hline \multicolumn{2}{|l|}{ Self-perceived health } & \multirow{5}{*}{$<0.001$} \\
\hline Very good & $14.7(12.6,16.8)$ & \\
\hline Good & $8.3(7.0,9.6)$ & \\
\hline Fair & $4.4(3.2,5.6)$ & \\
\hline Bad or very bad & $2.0(0.9,3.0)$ & \\
\hline
\end{tabular}

a Sample weights taken from the European Health Interview Survey (EHIS wave 2; ${ }^{\mathrm{b}}$ Engaging in musclestrengthening activities at least two times per week; ${ }^{\mathrm{c}}$ Ninety-five percent confidence interval; ${ }^{\mathrm{d}} p$-value from the chi-square test.

For smoking status and alcohol intake, we found no significant associations with meeting the MSA guidelines $(p>0.05)$. 
Table 3. Adjusted odds ratios (OR) of meeting the muscle-strengthening activity (MSA) guidelines ${ }^{\text {a }}$.

\begin{tabular}{|c|c|c|}
\hline Population Group & Adjusted OR (95\% CI $\left.{ }^{b}\right)$ & $p^{\mathrm{c}}$ \\
\hline \multicolumn{3}{|l|}{ All } \\
\hline \multicolumn{3}{|l|}{$\operatorname{Sex}$} \\
\hline Female & $0.51(0.39,0.66)$ & $<0.001$ \\
\hline Male & ref & \\
\hline \multicolumn{3}{|l|}{ Age } \\
\hline $18-24$ years & ref & \\
\hline $25-39$ years & $0.49(0.36,0.68)$ & $<0.001$ \\
\hline 40-64 years & $0.31(0.22,0.44)$ & $<0.001$ \\
\hline $65+$ years & $0.18(0.11,0.31)$ & $<0.001$ \\
\hline \multicolumn{3}{|l|}{ Urbanisation level } \\
\hline Densely populated area & ref & \\
\hline Moderately populated area & $0.80(0.60,1.06)$ & 0.118 \\
\hline Sparsely populated area & $0.63(0.48,0.84)$ & 0.002 \\
\hline \multicolumn{3}{|l|}{ Education level } \\
\hline High & ref & \\
\hline Medium & $0.50(0.39,0.64)$ & $<0.001$ \\
\hline Low & $0.23(0.14,0.38)$ & $<0.001$ \\
\hline \multicolumn{3}{|l|}{ Smoking status } \\
\hline Non-smokers & ref & \\
\hline Smokers & $0.97(0.76,1.25)$ & 0.824 \\
\hline \multicolumn{3}{|l|}{ Alcohol intake } \\
\hline Rarely or never & ref & \\
\hline 2-3 days per month & $1.25(0.89,1.76)$ & 0.193 \\
\hline $1-2$ days per week & $1.28(0.89,1.84)$ & 0.187 \\
\hline 3 or more days per week & $1.27(0.91,1.79)$ & 0.164 \\
\hline \multicolumn{3}{|l|}{ Body mass index } \\
\hline$<18.5$ & $0.80(0.36,1.77)$ & 0.574 \\
\hline $18.5-24.9$ & ref & \\
\hline $25-29.9$ & $0.95(0.73,1.24)$ & 0.708 \\
\hline$\geq 30$ & $0.55(0.36,0.86)$ & 0.008 \\
\hline \multicolumn{3}{|l|}{ Self-perceived health } \\
\hline Very good & ref & \\
\hline Good & $0.72(0.55,0.93)$ & 0.013 \\
\hline Fair & $0.60(0.41,0.86)$ & 0.005 \\
\hline Bad or very bad & $0.37(0.20,0.68)$ & 0.002 \\
\hline
\end{tabular}

${ }^{a}$ Engaging in muscle-strengthening activities at least two times per week; ${ }^{b}$ Ninety-five percent confidence interval; ${ }^{c} p$-value for adjusted odds ratio.

\section{Discussion}

In a large, population-representative sample, we found that the vast majority of Croatian adults do not meet the MSA guidelines. Lower odds of meeting the MSA guidelines were found for females, older age groups, inhabitants of sparsely populated areas, those with low education level, people with obesity, and those who did not rate their health as "very good". No significant associations with meeting the MSA guidelines were found for smoking status and alcohol intake.

Given the positive effects of muscle-strengthening activities on health [15,17-21,40], from a public health perspective, the results of our study are concerning. The percentage of adults meeting the MSA guidelines in Croatia is higher than in Japan [29] and similar to that of Australia [24], Korea [30], and the United States [34,41]. However, Croatia is among the European Union countries with the lowest prevalence of meeting the guidelines [27]. Potential reasons for the low involvement of Croatian adults in MSA could be a low motivation for physical activity in general and a lack of interest for MSA in particular. The 
low prevalence of meeting the MSA guidelines in Croatia might also be due to inadequate access to muscle-strengthening exercise facilities, programmes, and equipment, as well as a lack of financial support for MSA programs and promotion provided by the national and local-level governments. According to Eurobarometer data [42], only $7 \%$ of people in Croatia exercise in health and fitness centres. According to the Central Bureau of Statistics, in 2019, there were only 294 registered fitness centres in Croatia, that is, 1 centre per 14,622 inhabitants [43]. Given the low prevalence of meeting the MSA guidelines and relatively low accessibility of facilities that enable such activities in Croatia, there is a need for public health actions to promote MSA. A potential solution for this issue is the promotion of MSA outside fitness centres; for example, at home. With regards to the muscle hypertrophy, MSA using one's own body weight at home might be as effective as exercising with weights in a fitness centre. A recent meta-analysis did not find significant differences in the effects on muscle hypertrophy for exercising with lower loads and with heavy weights [44]. Additionally, fitness centres usually charge membership fees. One of the key perceived barriers for exercise and sport among Croatian adults [42] is that "it is too expensive". This barrier could be circumvented by promoting home-based MSA.

Findings on sociodemographic correlates of MSA in the current study were largely consistent with findings of previous studies. In line with our findings, previous studies have shown that being a female, older age, and lower education level are associated with lower odds of participation in MSA [45]. The lower odds of meeting the MSA guidelines among Croatian females could be explained by their motives for exercise. The most important motives for exercise among Croatian females were relaxation and fitness improvement, while the least important motive was the muscle mass gain [46]. Physiological changes associated with aging, including those affecting skeletal muscles, have a large impact on physical fitness [47]. The lower level of participation of the elderly in MSA might be partially explained by the overall decline in their physical fitness and mobility due to the ageing process. Older people are more susceptible to injuries, which may be another factor that deters them from participating in MSA [48,49]. Furthermore, the individuals with a low level of education are likely to have less knowledge about the health benefits of physical activity, compared with highly educated people [50]. It might be that the awareness of the importance of MSA is also lower among those with a low level of education, which would explain the lower odds of meeting the MSA guidelines in this population group. Furthermore, living in a sparsely populated area was negatively associated with MSA participation. This might be due to lower accessibility to facilities that offer musclestrengthening exercise programmes in rural areas, compared with urban areas.

Our findings are also in line with previous studies showing a lower prevalence of MSA among obese individuals $[41,51,52]$ and among those with poor self-rated health $[28,53,54]$. The lower participation in MSA among obese individuals might partially be explained by the fact that recommendations for the prevention and treatment of obesity are mainly focused on aerobic physical activities [19]. In light of our findings, and given that MSA may significantly contribute to achieving a negative energy balance $[15,19]$, it would be particularly important to target obese individuals in future MSA-promoting initiatives in Croatia. Furthermore, poor health may discourage or prevent people from participating in strenuous exercise. This may explain why the lowest participation in MSA was associated with people who rated their overall health as bad or very bad.

The key strengths of this study were the use of a large, nationally-representative sample of Croatian adults, which allowed us to make inferences about the population, and the use of standardised EHIS questionnaire, which allowed us to make comparisons with findings of EHIS surveys conducted in other European countries.

The key limitation of the study stems from its cross-sectional design; we were not able to draw conclusions about the direction of the relationships. Some of the relationships found in our study may be bidirectional. For example, it may be that people with poor health were less likely to engage in MSA, but it may also be that participation in MSA 
improved health of some participants. Future longitudinal studies on this topic are needed to elucidate the direction of the relationship.

\section{Conclusions}

We found that the vast majority of Croatian adults do not meet the MSA guidelines, and that lower odds of meeting the MSA guidelines are associated with female sex, older age groups, living in a sparsely populated area, having a low education level, being obese, and having a lower self-rated health. Public health initiatives to promote MSA in Croatia seem warranted, particularly in the population groups that are at the highest risk of not meeting the MSA guidelines. Given the very low prevalence of meeting MSA guidelines in Croatia, it seems reasonable to encourage public health agencies and other relevant governmental and non-governmental bodies to consider the development of comprehensive strategies for promoting MSA among adults.

Author Contributions: Conceptualization, Ž.P., D.J., H.R. and J.Č.; methodology, Ž.P. and D.J.; formal analysis, D.J. and Ž.P.; writing—original draft preparation, H.R., J.Č., Ž.P. and D.J.; writing-review and editing, H.R., J.Č., D.J. and Ž.P.; supervision, Ž.P. and D.J. All authors have read and agreed to the published version of the manuscript.

Funding: This research received no external funding.

Institutional Review Board Statement: The Ethics Committee of the Croatian Institute of Public Health approved the study and all respondents signed an informed consent form before participating in the study.

Informed Consent Statement: Informed consent was obtained from all participants involved in the study.

Data Availability Statement: Restrictions apply to the availability of these data. Data was obtained from Croatian Institute of Public Health with the permission of Croatian Institute of Public Health.

Conflicts of Interest: The authors declare no conflict of interest.

\section{References}

1. World Health Organization. Global Status Report on Noncommunicable Diseases; World Health Organization: Geneva, Switzerland, 2014.

2. Lee, I.M.; Shiroma, E.J.; Lobelo, F.; Puska, P.; Blair, S.N.; Katzmarzyk, P.T. Effect of physical inactivity on major non-communicable diseases worldwide: An analysis of burden of disease and life expectancy. Lancet 2012, 380, 219-229. [CrossRef]

3. World Health Organization. Global Health Risks: Mortality and Burden of Disease Attributable to Selected Major Risks; World Health Organization: Geneva, Switzerland, 2009.

4. Schnohr, P.; O'Keefe, J.H.; Lange, P.; Jensen, G.B.; Marott, J.L. Impact of persistence and non-persistence in leisure time physical activity on coronary heart disease and all-cause mortality: The Copenhagen City Heart Study. Eur. J. Prev. Cardiol. 2017, 24, 1615-1623. [CrossRef]

5. Bakker, E.A.; Sui, X.; Brellenthin, A.G.; Lee, D.C. Physical activity and fitness for the prevention of hypertension. Curr. Opin. Cardiol. 2018, 33, 394-401. [CrossRef]

6. Joseph, M.S.; Tincopa, M.A.; Walden, P.; Jackson, E.; Conte, M.L.; Rubenfire, M. The impact of structured exercise programs on metabolic syndrome and its components: A systematic review. Diabetes Metab. Syndr. Obes. Targets Ther. 2019, 12, 2395-2404. [CrossRef]

7. Moore, S.C.; Lee, I.M.; Weiderpass, E.; Campbell, P.T.; Sampson, J.N.; Kitahara, C.M.; Keadle, S.K.; Arem, H.; Berrington de Gonzalez, A.; Hartge, P.; et al. Association of leisure-time physical activity with risk of 26 types of cancer in 1.44 million adults. JAMA Intern. Med. 2016, 176, 816-825. [CrossRef] [PubMed]

8. World Health Organization. Global Recommendations on Physical Activity for Health; World Health Organization: Geneva, Switzerland, 2010.

9. Oja, P.; Titze, S. Physical activity recommendations for public health: Development and policy context. EPMA J. 2011, 2, 253-259. [CrossRef] [PubMed]

10. Kahlmeier, S.; Wijnhoven, T.M.A.; Alpiger, P.; Schweizer, C.; Breda, J.; Martin, B.W. National physical activity recommendations: Systematic overview and analysis of the situation in European countries. BMC Public Health 2015, 15, 133. [CrossRef] [PubMed]

11. Garber, C.E.; Blissmer, B.; Deschenes, M.R.; Franklin, B.A.; Lamonte, M.J.; Lee, I.M.; Nieman, D.C.; Swain, D.P. American College of Sports Medicine position stand. Quantity and quality of exercise for developing and maintaining cardiorespiratory, musculoskeletal, and neuromotor fitness in apparently healthy adults: Guidance for prescribing exercise. Med. Sci. Sports Exerc. 2009, 43, 1334-1359. [CrossRef] 
12. American College of Sports Medicine. American College of Sports Medicine position stand. Progression models in resistance training for healthy adults. Med. Sci. Sports Exerc. 2009, 41, 687-708. [CrossRef]

13. Jurakic, D.; Pedisic, Z. Croatian 24-h guidelines for physical activity, sedentary behaviour, and sleep: A proposal based on a systematic review of literature. Medicus 2019, 28, 143-153.

14. Pollock, M.L.; Evans, W.J. Resistance training for health and disease: Introduction. Med. Sci. Sports Exerc. 1999, 31, 10-11. [CrossRef] [PubMed]

15. Westcott, W.L. Resistance training is medicine: Effects of strength training on health. Curr. Sports Med. Rep. 2012, 11, 209-216. [CrossRef]

16. Liu, C.J.; Latham, N.K. Progressive resistance strength training for improving physical function in older adults. Cochrane Database Syst. Rev. 2009, 3. [CrossRef] [PubMed]

17. Braith, R.W.; Stewart, K.J. Resistance exercise training: Its role in the prevention of cardiovascular disease. Circulation 2006, 113, 2642-2650. [CrossRef] [PubMed]

18. Flack, K.D.; Davy, K.P.; Hulver, M.W.; Winett, R.A.; Frisard, M.I.; Davy, B.M. Aging, resistance training, and diabetes prevention. J. Aging Res. 2011, 2011, 127315. [CrossRef]

19. Strasser, B.; Arvandi, M.; Siebert, U. Resistance training, visceral obesity and inflammatory response: A review of the evidence. Obes. Rev. 2012, 13, 578-591. [CrossRef]

20. Hong, A.R.; Kim, S.W. Effects of resistance exercise on bone health. Endocrinol. Metab. 2018, 33, 435-444. [CrossRef]

21. O'Connor, P.J.; Herring, M.P.; Caravalho, A. Mental health benefits of strength training in adults. Am. J. Lifestyle Med. 2010, 4, 377-396. [CrossRef]

22. Ciolac, E.G.; Rodrigues da Silva, J.M. Resistance training as a tool for preventing and treating musculoskeletal disorders. Sports Med. 2016, 46, 1239-1248. [CrossRef]

23. Saeidifard, F.; Medina-Inojosa, J.R.; West, C.P.; Olson, T.P.; Somers, V.K.; Bonikowske, A.R.; Prokop, L.J.; Vinciguerra, V.; Lopez-Jimenez, F. The association of resistance training with mortality: A systematic review and meta-analysis. Eur. J. Prev. Cardiol. 2019, 26, 1647-1665. [CrossRef]

24. Bennie, J.A.; Pedisic, Z.; Van Uffelen, J.G.Z.; Charity, M.J.; Harvey, J.T.; Banting, L.K.; Vergeer, I.; Biddle, S.J.H.; Eime, R.M Pumping Iron in Australia: Prevalence, trends and sociodemographic correlates of muscle strengthening activity participation from a National sample of 195,926 adults. PLoS ONE 2016, 11, e0153225. [CrossRef] [PubMed]

25. Bennie, J.A.; Pedisic, Z.; Van Uffelen, J.G.Z.; Gale, J.; Banting, L.K.; Vergeer, I.; Stamatakis, E.; Bauman, A.E.; Biddle, S.J.H. The descriptive epidemiology of total physical activity, muscle-strengthening exercises and sedentary behaviour among Australian adults-Results from the National Nutrition and Physical Activity Survey. BMC Public Health 2016, 16, 73. [CrossRef] [PubMed]

26. Freeston, J.; Gale, J.; Mavros, Y.; Bennie, J.; Pedisic, Z.; Bauman, A.; Stamatakis, E. Associations between multiple indicators of socio-economic status and muscle-strengthening activity participation in a nationally representative population sample of Australian adults. Prev. Med. 2017, 102, 44-48. [CrossRef]

27. Bennie, J.A.; De Cocker, K.; Smith, J.J.; Wiesner, G.H. The epidemiology of muscle-strengthening exercise in Europe: A 28-country comparison including 280,605 adults. PLoS ONE 2020, 15, e0242220. [CrossRef]

28. Bennie, J.A.; Pedisic, Z.; Sunni, J.K.; Tokola, K.; Husu, P.; Biddle, S.J.H.; Vasankari, T. Self-reported health-enhancing physical activity recommendation adherence among 64,380 finnish adults. Scand. J. Med. Sci. Sports 2017, 27, 1842-1853. [CrossRef]

29. Harada, K.; Oka, K.; Ota, A.; Shibata, A.; Nakamura, Y. Prevalence and correlates of strength training among Japanese adults: Analysis of the SSF National Sports-Life Survey 2006. Int. J. Sport Health Sci. 2008, 6, 66-71. [CrossRef]

30. Bennie, J.A.; Ding, D.; Khan, A.; Stamatakis, E.; Biddle, S.J.H.; Kim, J. Run, lift, or both? Associations between concurrent aerobic-muscle strengthening exercise with adverse cardiometabolic biomarkers among Korean adults. Eur. J. Prev. Cardiol. 2020, 27, 738-748. [CrossRef]

31. Strain, T.; Fitzsimons, C.; Kelly, P.; Mutrie, N. The forgotten guidelines: Cross-sectional analysis of participation in muscle strengthening and balance \& co-ordination activities by adults and older adults in Scotland. BMC Public Health 2016, 16, A1108. [CrossRef]

32. Dankel, S.J.; Loenneke, J.P.; Loprinzi, P.D. Dose-dependent association between muscle strengthening activities and all-cause mortality: Prospective cohort study among a national sample of adults in the USA. Arch. Cardiovasc. Dis. 2016, 109, 626-633. [CrossRef]

33. Bennie, J.A.; Lee, D.; Khan, A.; Wiesner, G.H.; Bauman, A.E.; Stamatakis, E.; Biddle, S.J.H. Muscle-strengthening exercise among 397,423 U.S. adults: Prevalence, correlates, and associations with health conditions. Am. J. Prev. Med. 2018, 55, 864-874. [CrossRef]

34. Bennie, J.A.; De Cocker, K.; Teychenne, M.J.; Brown, W.J.; Biddle, S.J.H. The epidemiology of aerobic physical activity and muscle-strengthening activity guideline adherence among 383,928 U.S. adults. Int J. Behav. Nutr. Phys. Act. 2019, 16, 34. [CrossRef] [PubMed]

35. Rhodes, R.E.; Lubans, D.R.; Karunamuni, N.; Kennedy, S.; Plotnikoff, R. Factors associated with participation in resistance training: A systematic review. Br. J. Sports Med. 2017, 51, 1466-1472. [CrossRef] [PubMed]

36. Liangruenrom, N.; Craike, M.; Biddle, S.J.H.; Suttikasem, K.; Pedisic, Z. Correlates of physical activity and sedentary behaviour in the Thai population: A systematic review. BMC Public Health 2019, 19, 414. [CrossRef] [PubMed]

37. Eurostat. European Health Interview Survey (EHIS wave 2) Methodological manual; Eurostat: Luxembourg, 2013.

38. Croatian Institute of Public Health. Europska zdravstvena anketa u Hrvatskoj 2014-2015; European Health Interview Survey (EHIS); Osnovni Pokazatelji; Croatian Institute of Public Health: Zagreb, Croatia, 2016. 
39. Little, R.J.A.; Rubin, D.B. Statistical Analysis with Missing Data, 2nd ed.; Wiley \& Sons: Hoboken, NJ, USA, 2014.

40. Phillips, S.M.; Winett, R.A. Uncomplicated resistance training and health-related outcomes: Evidence for a Public Health mandate. Curr. Sports Med. Rep. 2010, 9, 208-213. [CrossRef] [PubMed]

41. Fleetwood Loustalot, S.A.; Kruger, C.; Kruger, J.; Buchner, D.M.; Fulton, J.E. Muscle-strengthening activities and participation among adults in the United States. Res. Q. Exerc. Sport 2013, 84, 30-38. [CrossRef] [PubMed]

42. European Commission. Special Eurobarometer 472: Sport and Physical Activity; European Commission, Directorate-General for Education, Youth, Sport and Culture: Brussels, Belgium, 2018.

43. Central Bureau of Statistics. Register of Business Entities; Central Bureau of Statistics: Zagreb, Croatia, 2019.

44. Schoenfeld, B.J.; Grgic, J.; Ogborn, D.; Krieger, J.W. Strength and hypertrophy adaptations between low- vs. high-load resistance training: A systematic review and meta-analysis. J. Strength Cond. Res. 2017, 31, 3508-3523. [CrossRef]

45. Nakamura, Y.; Harada, K. Promotion of strength trening. In Physical Activity, Exercise, Sedentary Behavior and Health.; Kanosue, K., Oshima, S., Cao, Z.B., Oka, K., Eds.; Springer: Tokyo, Japan, 2015; pp. $29-42$.

46. Jurakic, D.; Greblo, Z.; Andrijasevic, M. Motives for exercising in general population of Croatia. In Proceedings of the 7th International Scientific Conference on Kinesiology, Opatija, Croatia, 22-25 May 2014; Milanovic, D., Sporis, G., Eds.; Faculty of Kinesiology: Zagreb, Croatia, 2014; p. 369.

47. Garatachea, N.; Pareja-Galeano, H.; Sanchis-Gomar, F.; Santos-Lozano, A.; Fiuza-Luces, C.; Moran, M.; Emanuele, E.; Joyner, M.J.; Lucia, A. Exercise Attenuates the Major Hallmarks of Aging. Rejuvenation Res. 2015, 18, 57-89. [CrossRef]

48. Dergance, J.M.; Calmbach, W.L.; Dhanda, R.; Miles, T.P.; Hazuda, H.P.; Mouton, C.P. Barriers to and benefits of leisure time physical activity in the elderly: Differences across cultures. J. Am. Geriatr. Soc. 2003, 51, 863-868. [CrossRef] [PubMed]

49. Burton, E.; Hill, A.M.; Pettigrew, S.; Lewin, G.; Bainbridge, L.; Farrier, K.; Airey, P.; Hill, K.D. Why do seniors leave resistance training programs? Clin. Interv. Aging 2017, 12, 585-592. [CrossRef]

50. Mesters, L.; Wahl, S.; Van Keulen, H.M. Socio-demographic, medical and social-cognitive correlates of physical activity behaviour among older adults (45-70 years): A cross-sectional study. BMC Public Health 2014, 14, 647. [CrossRef]

51. Kruger, J.; Ham, S.A.; Prohaska, T.R. Behavioral risk factors associated with overweight and obesity among older adults: The 2005 National Health Interview Survey. Prev. Chronic Dis. 2009, 6, A14.

52. Trudelle-Jackson, E.; Jackson, A.W.; Morrow, J.R. Relations of meeting national public health recommendations for muscular strengthening activities with strength, body composition, and obesity: The women's injury study. Am. J. Public Health 2011, 101, 1930-1935. [CrossRef] [PubMed]

53. Galuska, D.A.; Earle, D.; Fulton, J.E. The epidemiology of U.S. adults who regularly engage in resistance training. Res. Q. Exerc. Sport 2002, 73, 330-334. [CrossRef] [PubMed]

54. Humphries, B.; Duncan, M.J.; Mummery, W.K. Prevalence and correlates of resistance training in a regional Australian population. Br. J. Sports Med. 2010, 44, 653-656. [CrossRef] [PubMed] 